\title{
Influence of the pin shape of the tool during friction stir welding on the process output parameters
}

\author{
A. Kh. Akhunova ${ }^{\dagger}$ M. F. Imayev, A. Kh. Valeeva \\ †akhunova.a.a@gmail.com \\ Institute for Metals Superplasticity Problems RAS, 39 S. Khalturin St., Ufa, 450001, Russia
}

In this paper, computer simulation of the friction stir welding (FSW) of AlMg6Mn0.6 aluminum alloy sheet blanks by means of the DEFORM-3D software package is carried out to select the optimum pin geometry based on the calculation of the displacement and speed of displacement of the material points. Pins in the shape of a cylinder and a truncated cone with the cone angles of $\alpha=10,20$, and $30^{\circ}$ were considered. The friction coefficient of 0.5 was assumed. Instrumental steel AISI-D2 was chosen as the material for the tool. To reduce the computation time and avoid the instability of solution, the model of welded blanks was built as a single body of $3 \mathrm{~mm}$ thickness and 40 and $30 \mathrm{~mm}$ length and width, respectively. The behavior of the AlMg6Mn0.6 alloy was described using the Johnson-Cook model. The FSW process was simulated the tool moving speed $v=2 \mathrm{~mm} / \mathrm{s}$, rotation frequency $\omega=1000 \mathrm{rpm}$ and axial force $P=25 \mathrm{kN}$. The initial temperature of the workpiece and the tool was $20^{\circ} \mathrm{C}$. When welding the blanks, the conditions of heat exchange with the environment were set. The simulation results solution have shown that the flow of the material of the workpiece depends on the shape of the pin and is different over the thickness of the workpiece. The material in the lower area of the workpiece is practically not subjected to mixing for all values of the cone angle of the pin, in contrast to the middle and upper areas of the workpiece, where the material is noticeably mixed. Of all the tips considered, the most preferred for the FSW is a pin in the form of a truncated cone with the cone angle of $10^{\circ}$, since it provides good mixing in the plane of the workpiece, the maximum displacement of the material towards the root of the weld, and also allows one to get the most symmetrical seam.

Keywords: friction stir welding, finite element simulation, pin geometry, aluminum alloy 5654.

\section{Introduction}

Friction stir welding (FSW) is widely used in various industries for joining metals and alloys that are poorly subjected to traditional types of welding [1-2]. FSW is mainly used for joining materials with a relatively low melting point, primarily aluminum alloys. According to this technology, sheet metal billets are welded using the friction forces created by the tool [3-4], which consists of a shoulder and a pin. The pin is inserted into the joint of the workpieces to a depth approximately equal to their thickness so that the shoulder touches the surfaces of the workpieces. Next, the tool, rotating at high speed, moves along the line of jointing of two rigidly fixed workpieces. As a result of the work of the sliding friction forces on the contact surfaces "shoulderworkpiece" and "pin-workpiece", friction heating of the metal to a plastic state occurs, which allows the tool to mix the material. The volume of the material, in which the seam is formed, is limited from above by the shoulder.

The choice of pin geometry is an important factor for effective FSW, because it affects heat generation, material flow, forces, and other output characteristics [3-5]. Recently, computer simulation has been widely used to select effective parameters of the FSW process, which can significantly reduce the cost of manufacturing an expensive special tool [6-10]. There is a fairly large number of works devoted to computer modeling of the FSW process, but almost all of them, with rare exceptions [11-13], were carried out in complex software products ANSYS, ABAQUS, COSMOS FloWORK [14-20].

In this work, we performed a three-dimensional finite element modeling of the FSW process of sheet blanks from aluminum alloy AlMg6Mn0.6 in the environment of the widely used engineering software product DEFORM-3D in order to select the optimal pin geometry based on the calculation of the displacement and speed of displacement of material points.

\section{Computer modelling}

The finite element modeling of the FSW process was performed using the DEFORM-3D software application package. To reduce the computation time and avoid solution instability, the workpieces were modeled as a single body with a thickness of $3 \mathrm{~mm}$, length and width of 40 and $30 \mathrm{~mm}$, respectively. The finite element model is shown in Fig. 1. The numbers of elements of the workpiece and the tool were equal to 60000 and 32000 , respectively. A finer breakdown into elements was carried out in the interaction zone between the shoulder and the workpiece. To prevent degradation of the computational mesh during the motion of the tool, an adaptive algorithm for its rebuilding (Arbitrary Lagrangian Eulerian) was used. 
The behavior of the workpiece material, AlMg6Mn0.6 aluminum alloy, was described using the Johnson-Cook model included in the standard DEFORM-3D library:

$$
\bar{\sigma}=\left[A+B\left(\varepsilon_{p}\right)^{n}\right]\left[1+C \ln \left(\frac{\varepsilon_{p}^{\prime}}{\varepsilon_{0}^{\prime}}\right)\right]\left[1-\left(\frac{T-T_{r}}{T_{m}-T_{r}}\right)^{m}\right],
$$

where $A$ is the yield stress, $B$ is the strain hardening coefficient, $n$ is the strain hardening index, $C$ is the speed sensitivity parameter, $m$ is the thermal softening coefficient, and $T, T_{r}, T_{m}$ are the current temperature, room temperature, and the melting temperature of the workpiece.

As the values of the model parameters, we used the values found for the foreign analogue AA5083 [21]: $A=167 \mathrm{MPa}$, $B=596 \mathrm{MPa}, n=0.551, C=0.001, \quad m=0.859, T_{r}=293 \mathrm{~K}$, $T_{m}=893 \mathrm{~K}$.

In order to reduce the calculation error, the thermophysical properties of the AlMg6Mn0.6 alloy were taken to be constant and equal to the values acquired by the material at a temperature of $600^{\circ} \mathrm{C}$. This temperature is close to the average temperature of this alloy during FSW. The following physical constants were set: density of $2640 \mathrm{~kg} / \mathrm{m}^{3}$, thermal conductivity of $122 \mathrm{~W} /(\mathrm{m} \cdot \mathrm{K})$, and heat capacity at constant pressure of $0.922 \mathrm{~kJ} /(\mathrm{kg} \cdot \mathrm{K})$.

When welding the workpiece, the conditions of heat exchange with the environment were set. The initial temperature of the workpiece, the tool and the environment was equal to $20^{\circ} \mathrm{C}$. Convection was set from all external surfaces with a heat transfer coefficient of $11 \mathrm{~W} /\left(\mathrm{m}^{2} \cdot \mathrm{K}\right)$.

The tool was taken as an absolutely rigid body, since the yield stress of its material is much higher than that of the workpiece. AISI-D2 tool steel was chosen as the material for the tool. We examined the pins in the form of a cylinder and a truncated cone with the cone angle of $\alpha=10,20$, and $30^{\circ}$ (Fig. 2). The diameter of the lower part of the pin in all cases was equal to $2 \mathrm{~mm}$. The friction coefficient was taken equal to 0.5 .

The FSW process was modeled in two stages. At the first stage, the pin was immersed in the workpiece, while the axis of the tool was tilted at an angle of $2^{\circ}$ relative to the normal to the workpiece. The immersion depth was $2.8 \mathrm{~mm}$, the immersion speed was $2 \mathrm{~mm} / \mathrm{s}$. At the second stage, welding was performed at a tool moving speed of $v=2 \mathrm{~mm} / \mathrm{s}$, a velocity of rotation $\omega=1000 \mathrm{rpm}$ and an axial force of $P=25 \mathrm{kN}$

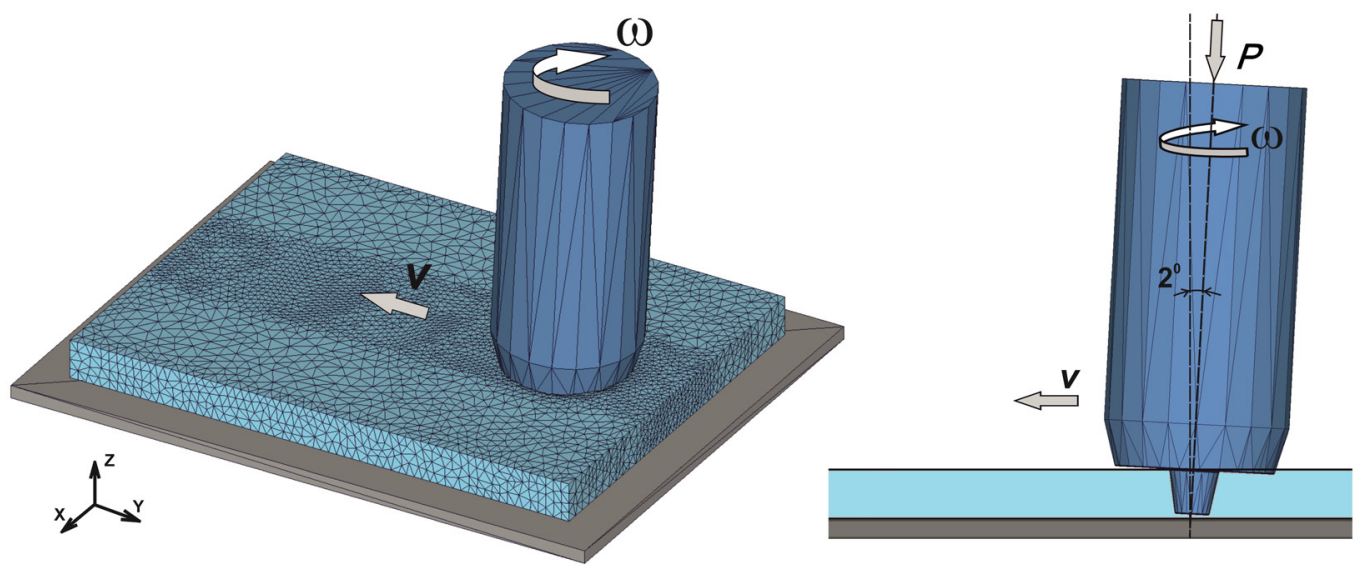

Fig. 1. (Color online) Finite element model of the workpiece and tool.
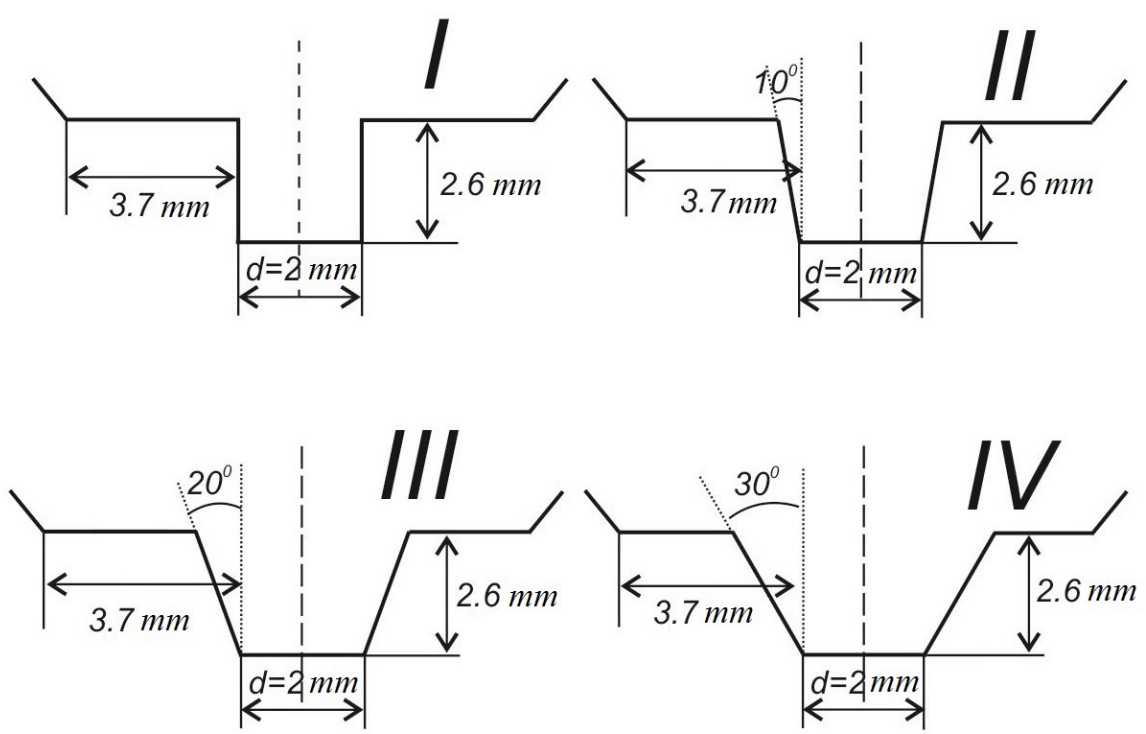

Fig. 2. Pin profiles considered. 
Basing on the results of an analysis of the distribution diagrams for the fields of absolute velocities of particles in the workpiece material near the tool, one can say that for $\alpha=0^{\circ}$ and $\alpha=10^{\circ}$ the field with the highest values of velocity is observed on the surface of the workpiece in the zone of its contact with the shoulder. With an increase in $\alpha$, the region of maximum velocities shifts deeper into the workpiece. At $\alpha=20^{\circ}$ and $\alpha=30^{\circ}$ there is a very inhomogeneous distribution of particle velocities along the pin (from $200 \mathrm{~mm} / \mathrm{s}$ near the shoulder to $25 \mathrm{~mm} / \mathrm{s}$ in the lower part of the pin).

From the distribution diagrams of displacements of the workpiece points, one can conclude that for all values of $\alpha$ the maximum displacements are observed in the upper region of the workpiece. This is due to the fact that initially the surface of the workpiece comes into contact with the tool (shoulder). Due to the occurrence of friction forces, the surface of the workpiece begins to heat up strongly, and, due to the combined action of forces, plastic deformation occurs. Then, following the upper layers, the material is mixed in the middle region of the workpiece in the zone of contact with the pin. The material in the lower region of the workpiece is practically not involved in mixing. For $\alpha=0^{\circ}$ and $\alpha=10^{\circ}$, in the transverse direction to the weld, the displacement does not exceed $3.50 \mathrm{~mm}$. With an increase in $\alpha$, the displacement values increase, and the heterogeneity of their distribution along the axis of the pin also increases. For $\alpha=20^{\circ}$ and $30^{\circ}$, displacements near the shoulder reach 4.38 and $5.25 \mathrm{~mm}$, respectively, while in the lower part of the pin the displacements for these angles are only $1.75 \mathrm{~mm}$. This is due to fact that with an increase in the angle of inclination of the cone, the area of the pin increases and the area of the shoulder decreases, which leads to an increase in displacements in the transverse direction to the weld.

In order to analyze the displacements of materials during the process, three points 1,2 and 3 located in the lower, middle and upper regions of the workpiece and initially contacting with the pin surface were chosen (Fig. 3). Fig. 3 shows the trajectories of the motion of these material points in space $(\Delta X, \Delta Y$, time) over a period of time from the onset of the motion of the pin along the OY axis to the stop of motion at the time $5 \mathrm{~s}$. Analysis of the simulation results presented in the figure allows one to draw the following conclusions:

- the material in the lower region of the workpiece (p. 1) practically does not undergo mixing at all values of the angle $\alpha$;

- in the middle (p. 2) and upper (p. 3) parts of the workpiece, the material is noticeably mixed, and the amplitude of displacements increases with increasing $\alpha$;

- the smallest number of rotations of material points $1-3$ is observed for the pin with $\alpha=30^{\circ}$;

-for p. 2, the final displacement along the $\mathrm{X}$ and $\mathrm{Y}$ axes does not exceed $1 \mathrm{~mm}$ for all angles $\alpha$;

- for p. 3, the maximum final displacement values of up to $4 \mathrm{~mm}$ are observed for $\alpha=0^{\circ}$ and $\alpha=20^{\circ}$, which indicates a violation of the symmetry of the seam and the formation of a bank on the running-on side.

Fig. 4 shows the displacements of points 1 to 3 along the $\mathrm{OZ}$ axis as functions of time from the onset of the pin motion along the OY axis to the stop at time $5 \mathrm{~s}$. The analysis of the displacements show that:

- at $\alpha=30^{\circ}$ and $\alpha=20^{\circ}$, large positive values of displacements of points 1 and 2 are observed, which, apparently, contributes to the formation of a bank on the surface of the workpiece;

- for $\alpha=0^{\circ}$ and $\alpha=10^{\circ}$, mostly negative displacement values occur for all points (i.e., directed to the root of the seam), with the largest displacements observed for $\alpha=10^{\circ}$.

It is known that during FSW, the main input of energy into the joint is carried out by the shoulder, while the pin promotes the spread of heat and plastic deformation over the thickness of the workpiece, and also intensifies the activation process of welded surfaces [11]. The flow of material to the root of the weld creates additional compression pressure, due to which the metal is densified (forged). In this regard, the shape of the pin that carries out the greatest displacement of the workpiece material in the vertical direction, i.e. towards the root of the weld, is considered to be the most favorable one.

Thus, a pin with a cone angle $\alpha=10^{\circ}$ should be considered the most effective. The distribution of velocities and particle displacements at such a pin is more uniform than that with the pins having cone angles $\alpha=20^{\circ}$ and $\alpha=30^{\circ}$. A pin with $\alpha=10^{\circ}$ allows not only performing a sufficiently large number of rotations of the particles of the workpiece, which improves
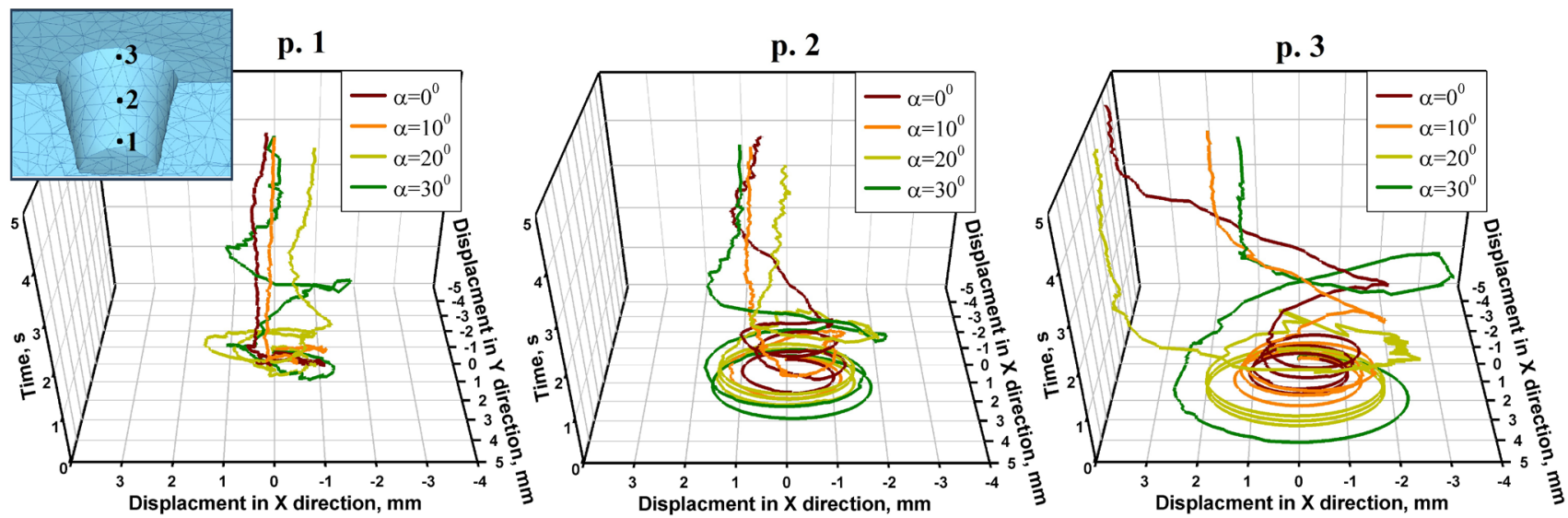

Fig. 3. (Color online) The trajectories of the motion of material points 1-3 in space ( $\Delta X, \Delta Y$, time) for the four angles of inclination of the cone $\alpha$. The initial locations of the points are shown in the figure. 


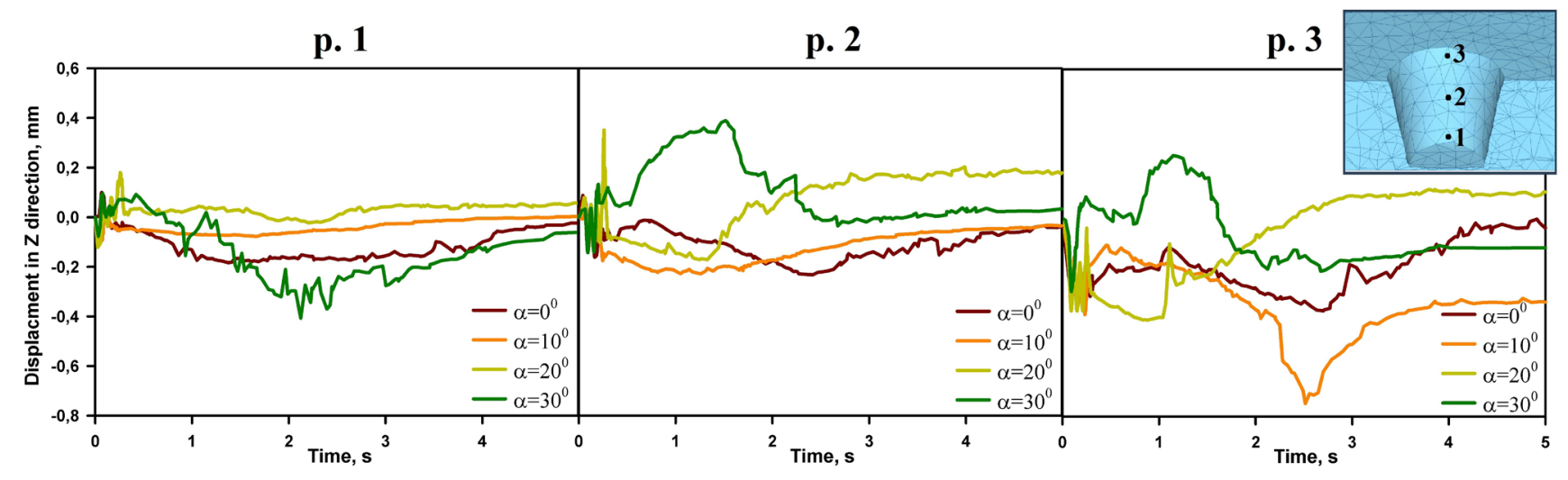

Fig. 4. (Color online) The dependence of the displacement along the axis OZ from the time of material points 1-3 for the four angles of inclination of the cone $\alpha$. The initial locations of the points are shown in the figure.

the quality of mixing, but also realizing maximum vertical displacements in the direction of the root of the seam, which increases the mixing area. A pin with $\alpha=10^{\circ}$ also allows one to get the most symmetrical seam.

\section{Conclusions}

1. Using computer simulation in the DEFORM-3D software environment, the influence of the geometric shape of the tool tip during friction stir welding on the output process parameters, such as the displacement of material points and the absolute speed of displacement, was studied.

2. It was found that the flow of material depends on the shape of the pin and is different along the thickness of the workpiece. The material in the lower region of the workpiece is practically not mixed for all cone angles of truncated coneshaped pin, in contrast to the middle and upper regions of the workpiece, where the material is noticeably mixed.

3. Of all the pins considered, the most preferable for FSW is a pin in the form of a truncated cone with a cone angle of $10^{\circ}$, because it provides good mixing in the plane of the workpiece, the maximum displacement of the material towards the root of the seam, and also allows one to get the most symmetrical seam.

Acknowledgements. The present work was accomplished according to the state assignment of IMSP RAS.

\section{Referencies}

1. S. Mironov, Y.S. Sato, H. Kokawa. Journal of Materials Science \& Technology. 34, 58 (2018). Crossref

2. H. Zhang, D. Wang, P. Xue, L. H. Wu, D. R. Ni, B. L. Xiao, Z. Y. Ma. Journal of Materials Science \& Technology. 34, 2183 (2018). Crossref

3. M. Elyasi, H. A. Derazkola, M. Hosseinzadeh. Proceedings of the Institution of Mechanical Engineers, Part B: J. of Engineering Manufacture. 230 (7), 1234 (2016). Crossref

4. K.K. Ramachandran, N. Murugan, S. Shashi Kumar. Materials Science and Engineering: A. 639, 219 (2015). $\underline{\text { Crossref }}$
5. M. Assidi, L. Fourment, S. Guerdoux, T. Nelson. International Journal of Machine Tools and Manufacture. 50 (2), 143 (2010). Crossref

6. X. He, F. Gu, A. Ball. Progress in Materials Science. 65, 1 (2014). Crossref

7. M. Mehta, G. M. Reddy, A.V. Rao, A. De. Defence Technology. 11, 229 (2015). Crossref

8. H. Su, C.S. Wu, M. Bachmann, M. Rethmeier. Materials and Design. 77, 114 (2015). $\underline{\text { Crossref }}$

9. Y. Zhu, G. Chen, Q. Chen, G. Zhang, Q. Shi. Materials and Design. 108, 400 (2016). Crossref

10. G. Chen, Q. Shi, Y. Fujiya, T. Horie. Journal of Materials Engineering and Performance. 23 (4), 1321 (2014). $\underline{\text { Crossref }}$

11. R. Jain, S. K. Pal, S. B. Singh. Journal of Manufacturing Processes. 23, 278 (2016). Crossref

12. R. Jain, S. K. Pal, S. B. Singh. The International Journal of Advanced Manufacturing Technology. 94, 1781 (2018). Crossref

13. A.L. Maystrenko, V.M. Nesterenkov, V.A. Dutka, V.A. Lukash, S.D. Malt, V.N. Tkach. Avtomaticheskaya Svarka. 1, 5 (2015). (in Russian)

14. G. Buffa, A. Ducato, L. Fratini. Finite Elements in Analysis and Design. 47, 470 (2011). Crossref

15. A. G. Boytsov, A. V. Lyushinsky, A. A. Baranov. Aerospace Instrumentation. 7, 3 (2015) (in Russian)

16. I. V. Sitnikov, E.S. Salomatov. Master's journal. 2, 84 (2014). (in Russian)

17. P.P. Kotlyshev. Friction stir welding. Rostov-on-Don, DGTU (2012) 137 p. (in Russian)

18. G. Chen, H. Li, G. Wang, Z. Guo, S. Zhang, Q. Dai, X. Wang, G. Zhang, Q. Shi. International Journal of Machine Tools and Manufacture. 124, 12 (2018). Crossref 19. G. Chen, Z. Feng, Y. Zhu, Q.Shi. Journal of Materials Engineering and Performance. 25 (9), 4016 (2016). Crossref

20. S. Ji, Q. Shi, L.Zhang, A.Zou, S. Gao, L.Zan. Computational Materials Science. 63, 218 (2012). Crossref

21. A.H. Clausen, T. Børvik, O.S. Hopperstad, A. Benallal. Materials Science and Engineering: A. 364, 260 (2004). Crossref 